\title{
Mutation in DNA gyrase of norfloxacin-resistant clinical isolates of Neisseria gonorrhoeae
}

\author{
Masatoshi Tanaka, Masako Otsuki, Takeshi Nishino, Intetsu Kobayashi, Tetsuro \\ Matsumoto, Joichi Kumazawa
}

\begin{abstract}
Background and Objectives: Recently a rapid decrease in the susceptibility of Neisseria gonorrhoeae isolates to fluoroquinolones has occurred and gonococcal fluoroquinolone resistance is now a significant problem in the treatment of gonorrhoea in Japan. Thus, in order to investigate the quinolone resistance mechanisms in clinical isolates of $N$ gonorrhoeae we studied an alteration in the DNA gyrase subunit A (GyrA) which is well-known as a common mechanism of bacterial quinolone resistance.

Materials and methods: Four clinical isolates of $N$ gonorrhoeae resistant to norfloxacin and 5 strains susceptible to norfloxacin, including 2 clinical isolates and 3 WHO reference strains, were tested in this study. To identify mutations in the GyrA genes of gonococcal strains, polymerase chain reaction and direct DNA sequencing were performed.

Results: A single base change (serine codon TCC changed to phenylalanine codon TTC), which resulted in an amino acid change in GyrA at position 91, was identified in all 4 norfloxacin-resistant strains for which the MICs of norfloxacin ranged from 1.0 to $8.0 \mu \mathrm{g} / \mathrm{ml}$, while no mutation within GyrA was detected in 5 norfloxacin-susceptible strains for which the MICs of norfloxacin ranged from 0.004 to $0.063 \mu \mathrm{g} / \mathrm{ml}$.

Conclusions: The results from this study suggest that the serine-91 to phenylalanine substitution in GyrA is probably an essential mutation in fluoroquinolone resistance in clinical isolates of $N$ gonorrhoeae.

(Genitourin Med 1996;72:295-297)
\end{abstract}

Keywords: Neisseria gonorrhoeae; quinolone resistance; mutation; DNA gyrase

Departmentof
Urology, Faculty of
Medicine, Kyushu
University, Fukuoka
M Tanaka
T Matsumoto
J Kumazawa
Department of
Miicrobiology, Kyoto
Pharmaceutical
University, Kyoto
M Otsuki
T Nishino
Division of
Chemotherapy,
Mitsubishi Kagaku
Bio-clinical
Laboratories Inc,
Tokyo, Japan
I Kobayashi
Address correspondence to:
Masatoshi Tanaka,
Experimental Retrovirology
Section, Medicine Branch
Bldg 10, Rm 5 A11, National
Cancer Institute, National
Institutes of Health, , 9000
Rockville Pike, Bethesda,
Maryland 20892, USA.
Accepted for publication
16 May 1995

Departmentof

Medicine, Kyushu

University, Fukuoka

M Tanaka

Thatsumoto

Department of

Microbiology, Kyoto

Pharmaceutical

M Otsuki

T Nishino

Division of

Chemotherapy,

Mitsubishi Kagaku

I Kobayashi

ence to: Experimental Retrovirolog Bldg 10, Rm 5A11 Nation Cancer Institute, Nationa Rrtutes of Health, 9000 Maryland 20892, USA. 16 May 1995

\section{Introduction}

Fluoroquinolones such as norfloxacin, ofloxacin, and ciprofloxacin exert excellent in vitro antimicrobial activity against Neisseria gonorrhoeae, including penicillin- and tetracycline-resistant strains. Fluoroquinolones have proven to be highly effective as oral singledose treatment for gonococcal infections. Thus, in the past decade, fluoroquinolone regimens have been used increasingly in developed countries for therapy of gonorrhoea, as well as genitourinary tract infections and other bacterial infections. However, the emergence of gonococcal isolates showing reduced susceptibility to fluoroquinolones has recently been reported in several countries. ${ }^{1-7}$ In Japan, gonococcal fluoroquinolone resistance is now a significant problem in the treatment of gonorrhea.$^{89}$ It is therefore important to study quinolone resistance mechanisms in clinical isolates of $\mathrm{N}$ gonorrhoeae.

In several bacterial species such as Escherichia coli and Staphylococcus aureus, two main mechanisms by which the bacteria acquire resistance to fluoroquinolones have been proposed. First, mutations in DNA gyrase subunit A (GyrA) and subunit B (GyrB) genes of the target DNA gyrase proteins lead to lower inhibitory activities of fluoroquinolones against DNA gyrase. In $E$ coli, mutation at serine- 83 in the GyrA is most commonly found in quinolone-resistant strains. ${ }^{1011}$ Second, an alteration in drug permeation is also known to be a role of resistance to quinolones. In $E$ coli, this phenomenon has been associated with mutations leading to decreasing amounts of the outer membrane protein OmpF. ${ }^{12-14}$ Furthermore, an active efflux system has recently been reported as the quinolone resistance mechanism in gram-negative bacteria. ${ }^{15}$

However, less is known about quinolone resistance mechanisms in gonococci. ${ }^{1617}$ Our previous investigation ${ }^{16}$ demonstrated that an alteration in drug permeability was associated with quinolone resistance in 2 of 4 norfloxacin-resistant isolates, while the remaining 2 isolates perhaps possess other quinolone mechanisms such as mutations in the target GyrA, because the 2 isolates accumulated norfloxacin as well as norfloxacin-susceptible strains. Thus, in this study, we analysed mutations within the GyrA gene in clinical isolates of $N$ gonorrhoeae showing in vitro resistance to norfloxacin.

\section{Materials and methods \\ Bacterial strains}

Six clinical strains of $N$ gonorrhoeae isolated from men with acute urethritis between February and July 1992 in Japan and three WHO $N$ gonorrhoeae reference strains (kindly supplied by JW Tapsall, Department of Microbiology, The Prince of Wales Hospital, Randwick, Australia) were used in this study. None of the six clinical strains were posttreatment isolates or repeat isolates from the same patients. All the clinical isolates tested were epidemiologically unrelated. $N$ gonorrhoea was identified as gram-negative diplococci and by oxidase reaction and sugar utilisation patterns. 
Antibiotic susceptibility testing

The minimum inhibitory concentration (MIC) for the 9 strains was determined using an agar dilution technique with a GC agar base (Becton Dickinson, USA) containing 1\% Iso VitaleX (Becton Dickinson) and 2-fold dilutions of antibiotic. Plates were inoculated with $5 \mu \mathrm{l}$ of $10^{6}$ colony-forming units (cfu)/ml of each isolate by a multipoint inoculator. The plates were incubated for 24 hours at $35^{\circ} \mathrm{C}$ in $5 \% \mathrm{CO}_{2}$ atmosphere. MICs were read as the lowest concentration of antibiotic that inhibited bacterial growth. The antibiotics tested were norfloxacin (Kyorin Pharmaceutical Co Ltd, Japan), ofloxacin (Daiichi Pharmaceutical Co Ltd, Japan), ciprofloxacin (Bayer Yakuhin Ltd, Japan), penicillin G (Meiji Seika, Japan), ceftriaxone (Hoffman-LaRoche Inc, USA), tetracycline (Sigma, USA), and spectinomycin (Upjohn Co, Canada). All of the antibiotics were obtained as powders of stated potency from their manufacturers. $\beta$ lactamase production was tested by an acidometric assay ( $\beta$-check; Pfizer Pharmaceuticals Inc, Japan).

\section{Extraction of DNA and synthesis of oligonucleotides}

Chromosomal DNA was extracted by the rapid boiling method described previously ${ }^{18}$ and subjected to polymerase chain reaction (PCR). To amplify a DNA fragment of the GyrA gene corresponding to amino acids positions 53 to 179, which includes the region of $N$ gonorrhoeae GyrA termed "the quinolone resistance-determining region" corresponding to amino acids positions 55 to 110 of gonococcal GyrA, ${ }^{17}$ two oligonucleotides (NGGYRA F1, 5'-TGCACCGGCGCGTACTGTAC-3'; NGGYRA R1, 5'-ACGAGCCGTTGACGAGCAGT-3') which were purchased from Takara Shuzo Co Ltd Biochemical Group (Shiga, Japan) were used. These primers were located within consensus amino acids of the bacterial GyrA proteins, and yielded a product of 384 bp DNA fragment after PCR amplification.

\section{$P C R$}

PCR amplification was performed in $20 \mu \mathrm{l}$ of a reaction mixture containing $5 \mathrm{pmol}$ each of the two primers, $20 \mathrm{nmol}$ each of the four deoxynucleotide triphosphates, $10 \mathrm{mM}$ Tris-
$\mathrm{HCl}(\mathrm{pH} \mathrm{8.3)}, 50 \mathrm{mM} \mathrm{KCl}, 1.5 \mathrm{mM} \mathrm{MgCl}$, $0.001 \%$ gelatin, and $0.5 \mathrm{U}$ of Taq DNA polymerase (Takara, Japan). Thirty cycles were performed for each reaction, with one cycle consisting of $15 \mathrm{~s}$ at $94^{\circ} \mathrm{C}, 30 \mathrm{~s}$ at $60^{\circ} \mathrm{C}$, and $30 \mathrm{~s}$ at $74^{\circ} \mathrm{C}$.

\section{Direct DNA sequencing}

PCR-amplified DNA was sequenced with synthetic oligonucleotide primer (NGGYRA F1 or NGGYRA R1) by the dideoxy-chain termination method, ${ }^{19}$ using the BcaBEST dideoxy sequencing kit dCTP version (Takara, Japan) and $\left[a-{ }^{35} S\right]$ dCTP (Amersham, UK). The samples were electrophoresed in 5\% Long Ranger Gel (AT Biochem, USA) containing $7 \mathrm{M}$ urea at $1800 \mathrm{~V}$. The gel was dried and exposed to $x$ ray film (Fuji Photo Film, Japan).

\section{Results}

The antimicrobial susceptibilities of the nine gonococcal strains to norfloxacin, ofloxacin, ciprofloxacin, penicillinG, ceftriaxone, tetracycline, and spectinomycin are summarised in table 1 . All of the nine strains were negative for $\beta$-lactamase production. The isolates $\mathrm{A}-10$ (MIC; $8.0 \mu \mathrm{g} / \mathrm{ml}$ ) and A-22 (MIC; $4.0 \mu \mathrm{g} / \mathrm{ml}$ ) were highly resistant to norfloxacin and A-55 (MIC; $1.0 \mu \mathrm{g} / \mathrm{ml}$ ) and A-161 (MIC; 2.0 $\mu \mathrm{g} / \mathrm{ml}$ ) were moderately resistant to norfloxacin. The strains A-37, A-69, WHO-A, WHO-B, and WHO-D were susceptible to norfloxacin, for which MICs of norfloxacin were $0.063,0.004,0.004,0.031$, and 0.063 $\mu \mathrm{g} / \mathrm{ml}$, respectively. The four norfloxacinresistant isolates showed 16 - to 2000-fold higher MIC values of the antibiotic, as compared with those of the 5 norfloxacin-susceptible strains, and were cross-resistant to ofloxacin and ciprofloxacin. Furthermore, the high-level norfloxacin-resistant isolates (A-10 and A-22) showed less susceptibilities to penicillin, ceftriaxone, and tetracycline than did the norfloxacin-susceptible isolates (A-37 and A-69).

In the previous study, ${ }^{16}$ to research the other quinolone resistance mechanism of alteration in drug permeability in gonococci, we measured intracellular accumulation of norfloxacin in the same six clinical and three WHO strains tested in the present investigation. Among the four norfloxacin-resistant iso-

Table 1 Antimicrobial susceptibility of clinical isolates of $N$ gonorrhoeae and norfloxacin accumulation by those gonococcal cells

\begin{tabular}{|c|c|c|c|c|c|c|c|c|}
\hline \multirow[b]{2}{*}{ Strain } & \multicolumn{7}{|c|}{$\operatorname{MIC}(\mu \mathrm{g} / \mathrm{ml})^{\star}$} & \multirow{2}{*}{$\begin{array}{l}\text { Accumulation of } \\
\text { NFLX } \\
\text { ( } \mathrm{ng} / \mathrm{mg} \text { of dry cells, } \\
\text { after } 20 \text { min) } t\end{array}$} \\
\hline & $N F L X$ & $O F L X$ & $C P F X$ & $P C G$ & CTRX & $T C$ & $S P C M$ & \\
\hline $\begin{array}{l}\text { A-10 } \\
\text { A-22 } \\
\text { A-55 } \\
\text { A-161 } \\
\text { A-37 } \\
\text { A-69 } \\
\text { WHO-A } \\
\text { WHO-B } \\
\text { WHO-D }\end{array}$ & $\begin{array}{l}8 \cdot 0 \\
4 \cdot 0 \\
1.0 \\
2 \cdot 0 \\
0.063 \\
0.004 \\
0.004 \\
0.031 \\
0.063\end{array}$ & $\begin{array}{l}1.0 \\
1.0 \\
0.5 \\
0.25 \\
0.063 \\
0.002 \\
0.004 \\
0.016 \\
0.063\end{array}$ & $\begin{array}{ll} & 0.5 \\
0.5 \\
0.125 \\
0.125 \\
0.016 \\
\leqslant 0.001 \\
\leqslant & 0.001 \\
0.016 \\
0.004\end{array}$ & $\begin{array}{l}0.5 \\
0.5 \\
0.25 \\
0.063 \\
0.063 \\
0.063 \\
0.008 \\
0.25 \\
1.0\end{array}$ & $\begin{array}{r}0.031 \\
0.016 \\
0.016 \\
0.016 \\
0.008 \\
0.004 \\
\leqslant 0.001 \\
0.004 \\
0.031\end{array}$ & $\begin{array}{l}2 \cdot 0 \\
2 \cdot 0 \\
2 \cdot 0 \\
0 \cdot 5 \\
1 \cdot 0 \\
0 \cdot 25 \\
0 \cdot 25 \\
0 \cdot 125 \\
2 \cdot 0\end{array}$ & $\begin{array}{r}16 \cdot 0 \\
16 \cdot 0 \\
16 \cdot 0 \\
16 \cdot 0 \\
32 \cdot 0 \\
8 \cdot 0 \\
32 \cdot 0 \\
8 \cdot 0 \\
8 \cdot 0\end{array}$ & $\begin{array}{r}0 \\
48 \\
54 \\
0 \\
20 \\
29 \\
22 \\
87 \\
48\end{array}$ \\
\hline
\end{tabular}

${ }^{\star}$ NFLX, norfloxacin; OFLX, ofloxacin; CPFX, ciprofloxacin; PCG, penicillinG; CTRX, ceftriaxsone; TC, tetracycline; SPCM, spectinomycin. 
Table 2 Analysis of GyrA mutation in clinical isolates of $N$ gonorrhoeae

\begin{tabular}{lllll}
\hline \multirow{2}{*}{$\begin{array}{l}\text { MIC of } \\
\text { NFL } X^{\star} \\
(\mu g / m l)\end{array}$} & \multicolumn{2}{l}{ GyrA mutation } \\
\cline { 3 - 5 } & Codon & Nucleotide changed & Amino acid changed \\
\hline A-10 & 8.0 & 91 & TCC $\rightarrow$ TTC & Ser $\rightarrow$ Phe \\
A-22 & 4.0 & 91 & TCC $\rightarrow$ TTC & Ser $\rightarrow$ Phe \\
A-55 & 1.0 & 91 & TCC $\rightarrow$ TTC & Ser $\rightarrow$ Phe \\
A-161 & 2.0 & 91 & TCC $\rightarrow$ TTC & Ser $\rightarrow$ Phe \\
A-37 & 0.063 & & None & None \\
A-69 & 0.004 & & None & None \\
WHO-A & 0.004 & & None & None \\
WHO-B & 0.031 & & None & None \\
WHO-D & 0.063 & & None & None \\
\hline
\end{tabular}

«NFLX, norfloxacin. tion corresponding to serine-83 in $E$ coli in clinical isolates of $N$ gonorrhoeae. ${ }^{20}$

Our previous study ${ }^{16}$ demonstrated that the norfloxacin-resistant strains A-10 and A-161 carrying a mutation in their GyrA did not accumulate norfloxacin, whereas the other norfloxacin-resistant strains A-22 and A-55 accumulated norfloxacin as well as norfloxacin-susceptible strains. It is therefore suggested that both alteration in drug permeability and change in GyrA may relate to fluoroquinolone resistance in the strains A-10 and $\mathrm{A}-161$.

1 Gransden WR, Warren CA, Phillips I, Hodges M, Barlow D. Decreased susceptibility of Neisseria gonorrhoeae to ciprofloxacin. Lancet 1990;335:51.

2 Jephcott AE, Turner A. Ciprofloxacin resistance in gonococci. Lancet 1990;335:165.

mulate norfloxacin after 20 minutes, whereas the strains A-22 and A-55 accumulated norfloxacin as well as norfloxacin-susceptible strains (table 1).

Nucleotide and amino acid changes within the quinolone resistance-determining region are shown in table 2 . A single base change (serine codon TCC changed to phenylalanine codon TTC), which resulted in an amino acid change in GyrA at position 91, was identified in all of the four gonococcal isolates (A-10, A$22, A-55$, and A-161) resistant to norfloxacin, while in norfloxacin-susceptible strains (A-37, A-69, WHO-A, WHO-B, and WHO-D), no mutation within the quinolone resistancedetermining region in GyrA was detected.

\section{Discussion}

Belland et $a l^{17}$ have recently generated a series of ciprofloxacin-resistant mutants by passaging $N$ gonorrhoeae in the presence of increasing concentrations of the antibiotic and examined whether mutations occurred in DNA gyrase genes. Their results demonstrated that the serine-91 (serine-91 in gonococcal Gyr $A$ corresponds to serine-83 in $E$ coli) to phenylalanine substitution in GyrA may be an essential mutation in the laboratory variants of gonococci showing ciprofloxacin resistance.

We performed sequencing the quinolone resistance-determining region within GyrA gene in clinical isolates of $N$ gonorrhoeae resistant to norfloxacin. All four norfloxacin-resistant isolates (A-10, A-22, A-55, and A-161) for which the MICs of norfloxacin ranged from 1.0 to $8.0 \mu \mathrm{g} / \mathrm{ml}$ had the same amino acid substitution at serine-91 to phenylalanine identified in the laboratory variants resistant to ciprofloxacin by Belland et al, while no mutation in the quinolone resistance-determining region within GyrA gene was detected in five norfloxacin-susceptible strains for which the MIC of norfloxacin ranged from 0.004 to $0.063 \mu \mathrm{g} / \mathrm{ml}$. Our results and Belland's indicate that the serine to phenylalanine substitution at position 91 may be an essential mutation in both laboratory variants and clinical isolates of $N$ gonorrhoeae resistant to fluoroquinolones. More recently, another study has also reported the same mutation of serine to phenylalanine in neisserial GyrA at the posi-
3 Clendennen III TE, Hames CS, Kees ES, et al. In vitro antibiotic susceptibilities of Neisseria gonorrhoeae isolates in the Philippines. Antimicrob Agents Chemother 1992, 36:277-82.

4 Bogaerts J, Tello WM, Akingeneye J, Mukantabana V, Van Dyck E, Piot P. Effectiveness of norfloxacin and ofloxacin for treatment of gonorrhoea and decrease of in vitro susceptibility to quinolones
Genitourin Med 1993;69:196-200

5 Knapp JS, Washington JA, Doyle LJ, Neal SW, Parekh MC, Rice RJ. Persistence of Neisseria gonorrhoeae strain with decreased susceptibilities to ciprofloxacin and ofloxacin in Cleveland, Ohio, from 1992 through 1993. Antimicrob Agents Chemother 1994;38:2194-6.

6 Knapp JS, Ohye R, Neal SW, Parekh MC, Higa H, Rice RJ. Emerging in vitro resistance to quinolones in penicillinase-producing Neisseria gonorrhoeae strains in Hawaii. Antimicrob Agents Chemother 1994;38:2200-3.

$7 \mathrm{Kam} \mathrm{KM}, \mathrm{LOKK}$, Ho NgK, Cheung MM. Rapid decline in penicillinase-producing Neisseria gonorrhoeae in Hong Kong associated with emerging 4-fluoroquinolone resistance. Genitourin Med 1995;71:141-4.

8 Tanaka M, Kumazawa J, Matsumoto T, Kobayashi I. High prevalence of Neisseria gonorrhoeae strains with reduced prevalence of Neisseria gonorrhoeae strains with reduced susceptibility to fluor

9 Tanaka M, Matsumoto T, Kobayashi I, Uchino U, Kumazawa J. Emergence of in vitro resistance to fluoroquinolones in Neisseria gonorrhoeae isolated in Japan. Antimicrob Agents Chemother 1995;39:2367-70.

10 Cullen ME, Wyke AW, Kuroda R, Fisher LM. Cloning and characterization of a DNA gyrase gene from Escherichia coli that confers clinical resistance to 4 quinolones. Antimicrob Agents Chemother 1989;33: 886-94.

11 Yoshida $H$, Bogaki $M$, Nakamura $M$, Nakamura $S$ Quinolone resistance-determining region in the DNA Quinolone resistance-determining region in the DNA gyrase GyrA gene of Escheric

12 Cohen SP, McMurry LM, Hooper DC, Wolfson JS, Levy SB. Cross-resistance to fluoroquinolones in multiple antibiotic-resistant (Mar) Escherichia coli selected by tetracycline or chloramphenicol: decreased drug accumulation associated with membrane change in addition to OmpF reduction. Antimicrob Agents Chemother 1989;33 1318-25.

13 Hirai $\mathrm{K}$, Aoyama $\mathrm{H}$, Irikura $\mathrm{T}$, Iyobe $\mathrm{S}$, Mitsuhasi $\mathrm{S}$. coli. Antimicrob Agents Chemother 1986;29:535-8.

14 Hooper DC, Wolfson JS, Bozza MA, Ng EY. Genetics and regulation of outer membrane protein by quinolone resisregulation of outer membrane protein by quinolone resistance loci nfxB, nfxC, and

15 Ishii $\mathrm{H}$, Sato $\mathrm{K}$, Hoshino $\mathrm{K}$, et al. Active efflux of ofloxacin by a high quinolone-resistant strain of Proteus vulgaris. $f$ Antimicrob Chemother 1991;28:827-36.

16 Tanaka M, Fukuda H, Hirai K, Hosaka M, Matsumoto T Kumazawa J. Reduced uptake and accumulation of norfloxacin in resistant strains of Neisseria gonorrhoeae isolated in Japan. Genitourin Med 1994;70:253-5.

17 Belland RJ, Morrison SG, Ison C, Huang WM. Neisseria gonorrhoeae acquires mutations in analogous regions of GyrA and parC in fuoroquinolone resistant isolates. Microbiol 1994;14:371-80.

18 Toshida $H$, Nakamura $M$, Bogaki $M$, Ito $H$, Kojima $T$, Hattori H, Nakamura S. Mechanism of action of quinolones against Escherichia coli DNA gyrase.

19 Messing J. New M13 vectors for cloning. Methods Enzymol 1983;101:20-78.

20 Deguchi T, Yasuda M, Asano $M$, et al. DNA gyrase mutations in quinolone-resistant clinical isolates of Neisseri gonorrhoeae. Antimicrob Agents Chemother 1995;39:561-3. ofloxacin for treatment of gonorrhoea and decrease of in Difference in susceptibility to quinolones outer membrane mutants of Salmonella typhimurium and Escherichia 